\title{
Analysis of T-DNA integration and generative segregation in transgenic winter triticale ( $x$ Triticosecale Wittmack)
}

\author{
Goetz Hensel $^{1 * \dagger}$, Sylwia Oleszczuk ${ }^{2 \dagger}$, Diaa Eldin S Daghma ${ }^{3,4}$, Janusz Zimny², Michael Melzer ${ }^{3}$
} and Jochen Kumlehn ${ }^{1}$

\begin{abstract}
Background: While the genetic transformation of the major cereal crops has become relatively routine, to date only a few reports were published on transgenic triticale, and robust data on T-DNA integration and segregation have not been available in this species.

Results: Here, we present a comprehensive analysis of stable transgenic winter triticale cv. Bogo carrying the selectable marker gene HYGROMYCIN PHOSPHOTRANSFERASE (HPT) and a synthetic green fluorescent protein gene (gfp). Progeny of four independent transgenic plants were comprehensively investigated with regard to the number of integrated T-DNA copies, the number of plant genomic integration loci, the integrity and functionality of individual T-DNA copies, as well as the segregation of transgenes in $T_{1}$ and $T_{2}$ generations, which also enabled us to identify homozygous transgenic lines. The truncation of some integrated T-DNAs at their left end along with the occurrence of independent segregation of multiple T-DNAs unintendedly resulted in a single-copy segregant that is selectable marker-free and homozygous for the gfp gene. The heritable expression of gfp driven by the maize UBI- 1 promoter was demonstrated by confocal laser scanning microscopy.
\end{abstract}

Conclusions: The used transformation method is a valuable tool for the genetic engineering of triticale. Here we show that comprehensive molecular analyses are required for the correct interpretation of phenotypic data collected from the transgenic plants.

Keywords: Agrobacterium, Winter triticale (x Triticosecale Wittmack), Sexual transmission, Transgene expression, gfp, Copy number

\section{Background}

Triticale, the artificial wheat $\mathrm{x}$ rye amphiploid, was created in an attempt to combine the grain quality and productivity of wheat with the superior performance of rye in marginal environments. Since the development of the early hybrids, substantial breeding progress has been made by conventional means. Nevertheless, the global cropping area devoted to triticale remains low, and the bulk of its production is concentrated in central and eastern Europe [1]. Given the prevailing climatic conditions in this region, $>90 \%$ of the crop is represented by winter

\footnotetext{
* Correspondence: hensel@ipk-gatersleben.de

${ }^{\dagger}$ Equal contributors

'Leibniz Institute of Plant Genetics and Crop Plant Research (IPK), Plant

Reproductive Biology, Corrensstr. 3, 06466, Gatersleben, Germany

Full list of author information is available at the end of the article
}

(vernalization-requiring) cultivars. Its major end-uses are as feed or fodder, but improvements in its grain milling and bread making quality could allow an extension to its use in human consumption or as an industrial feedstock. A particularly attractive prospect lies in its use as a source of bioenergy, but generating the necessary significant changes to the plant to allow this will probably require genetic modification. Hence there is a need to develop robust protocols for its genetic transformation.

The genetic engineering of triticale is still in its infancy. The direct delivery of DNA into protoplasts has achieved transient transgene expression, but not stable integration $[2,3]$. Difficulties in regenerating plants from isolated protoplasts have prompted the exploration of more readily regenerable explant materials, among which the

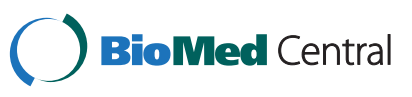


immature embryo has proven to be the most promising [4-7]. The earliest reported stable transgenic triticale plants relied on the biolistic treatment of immature embryo scutella [8]. A similar approach targeting haploid embryo-like structures resulted in only the transient expression of the transgene and no adult plants were regenerated [9]. A first applicative approach was published by Doshi et al. (2007) who used the embryo-specific LTP1 promoter to show the effect of the $C 1$ and Bperu maize genes on anthocyanin biosynthesis in triticale [10].

Agrobacterium-mediated gene transfer has proven to be an effective means of transforming each of the major cereal species, including triticale [11-13]. For the latter however, robust data on T-DNA integration and segregation were not provided thus far. Using plants produced by means of a previously published protocol [13], we here provide comprehensive information on transgenic triticale in terms of T-DNA integration, copy number, integrity and inheritance. Moreover, we provide evidence of consistent transgene expression across generations.

\section{Results}

\section{Primary transgenic plants}

Primary transgenic triticale plants that we had reported on in a previous article presenting protocols for several small grain cereals [13] were subjected in the present study to a comprehensive analysis. In this context, we also provide some complementary information on the elaboration of the transformation protocol previously

Table 1 Effect of pre-cultivation, A. tumefaciens strain and co-cultivation medium on the generation of stable transgenic triticale

\begin{tabular}{|c|c|c|}
\hline Strain & $\begin{array}{l}\text { Pre-culture time and } \\
\text { co-culture conditions }\end{array}$ & $\begin{array}{l}\text { Transgenic lines } \\
\text { per } 100 \text { IEs }\end{array}$ \\
\hline \multirow[t]{7}{*}{ AGL-1/ pYF133 } & $0 \mathrm{~d}, \mathrm{BCCM}$ & - \\
\hline & $0 \mathrm{~d}, \mathrm{WCCM}$ & - \\
\hline & $5 \mathrm{~d}, \mathrm{BCCM}$ & - \\
\hline & $5 \mathrm{~d}, \mathrm{WCCM}$ & - \\
\hline & $2 \mathrm{~d}, \mathrm{BCCM}$, filter paper & - \\
\hline & $5 \mathrm{~d}, \mathrm{BCCM}$, filter paper & - \\
\hline & $5 \mathrm{~d}$, WCCM, filter paper & - \\
\hline \multirow[t]{7}{*}{ LBA4404/ pSB187 } & $0 \mathrm{~d}, \mathrm{BCCM}$ & - \\
\hline & $0 \mathrm{~d}, \mathrm{WCCM}$ & - \\
\hline & $5 \mathrm{~d}, \mathrm{BCCM}$ & - \\
\hline & $5 \mathrm{~d}, \mathrm{WCCM}$ & - \\
\hline & $2 \mathrm{~d}, \mathrm{BCCM}$, filter paper & 3.6 \\
\hline & $5 \mathrm{~d}, \mathrm{BCCM}$, filter paper & 4.0 \\
\hline & $5 \mathrm{~d}$, WCCM, filter paper & - \\
\hline
\end{tabular}

A set of 50 IEs was processed per treatment. BCCM - barley co-culture medium, WCCM - wheat co-culture medium [13], IEs - immature embryos. published. As shown in Table 1, a two or five day period of pre-culturing (prior to exposure to A. tumefaciens) was required to obtain transgenic plants. Moreover, inoculation with Agrobacterium proved successful provided the immature embryos were stacked on filter paper moistened with liquid co-cultivation medium, rather than being submerged in the medium. Table 1 further shows, that transgenic plants were exclusively obtained when barley co-culture medium (BCCM) was used, whereas wheat co-culture medium (WCCM) failed to give rise to transgenics under the same conditions. Likewise, a hypervirulent derivative of A. tumefaciens strain LBA4404 resulted in the delivery of transgenic regenerants, whereas AGL-1 surprisingly did not do so under the conditions tested. The expression of $g f p$ was monitored throughout the transformation process (Figure 1A-J). After three days of co-cultivation with $A$. tumefaciens, fluorescing foci were visible at the margin of scutella of the immature embryos. After a further 3-6 weeks, GFP accumulation was particularly strong in the rapidly growing portion of the callus (Figure 1F-H), whereas emerging leaves and roots showed fluorescence of lower intensity. The transgenic regenerants confirmed by a PCR-based amplification of a $g f p$ fragment did not show any obvious morphological effect associated with transgenicity.

\section{Number, integrity and generative transmission of integrated T-DNAs}

Pollen produced by each of the four primary transgenic plants segregated with respect to $g f p$ expression (Figure 1I). When embryos formed by the primary transgenic plants were germinated on a medium containing hygromycin, $g f p$ expression was strong in both the scutellum and the emerging root, with a particularly high level in the root tip (Figure 1J). The selective medium discriminated between transgene carriers and non-carriers, with the former developing normally and the latter no longer able to grow after the emergence of the coleoptile, and unable to synthesize chlorophyll (Figure 2). The observed segregation ratio was consistent in three of the four cases with the presence of a single T-DNA insertion locus, while the progeny of the primary transgenic TG5E03 included significantly fewer transgene carriers than expected from a monogenic segregation (Table 2).

In order to comprehensively analyse the independent transgenic events obtained, $\mathrm{T}_{1}$ siblings were subjected to DNA gel blot analysis successively using HPT and $g f p$ probes in order to characterize the integration sites. The $g f p$-profile of progeny of TG5E01 is given as an example in Figure 3. The HPT profiles shown in Figure 4A indicated that the number of T-DNA copies present in TG5E01, TG5E02, TG5E03 and TG5E04 was, respectively, two, one, two and two, while the $g f p$ 

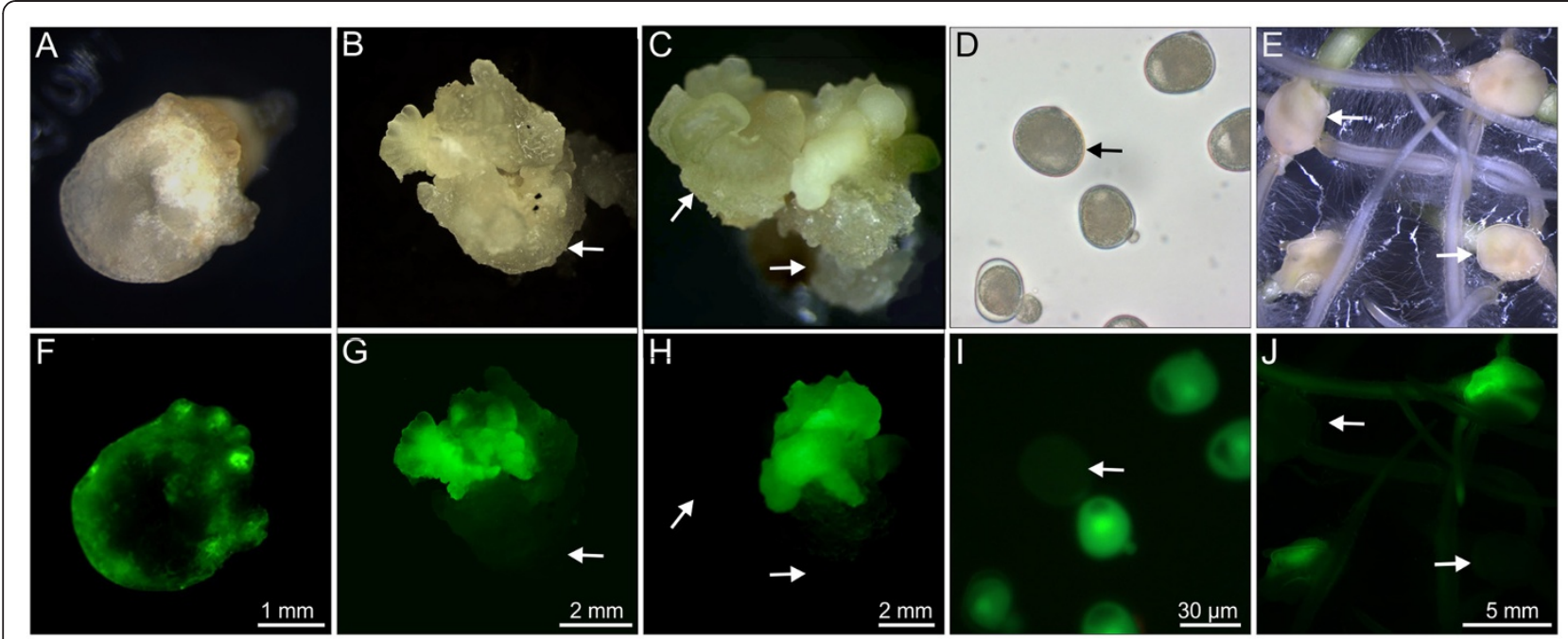

Figure 1 GFP accumulation in transgenic lines as shown by correlative microscopy using white light (A-E) and excitation by far blue light (F-J). Immature embryos (A, F) three days, (B, G) three weeks and (C, H) six weeks after co-culture with Agrobacterium; (D, I) immature pollen formed by the To plant TG5E02 isolated from anthers, collected in $0.4 \mathrm{M}$ mannitol and examined under a fluorescence microscope; (E, $\mathbf{J}$ ) immature $\mathrm{T}_{1}$ embryos from TG5E03 were germinated on K4N medium and their roots examined 5 days after embryo isolation. Non-transgenic tissue domains and segregants are indicated by arrows in $\mathbf{B}, \mathbf{C}, \mathbf{D}$ and $\mathbf{E}$ and their fluorescence microscopic counterparts $\mathbf{G}, \mathbf{H}, \mathbf{I}$ and $\mathbf{J}$, where no or only background fluorescence is seen in these positions. Note that the ratios of transgenic and non-transgenic individuals displayed in $\mathbf{I}$ and $\mathbf{J}$ are not representative.

probe also highlighted a third copy in TG5E01 (Figure 3). The analysis also showed that all three T-DNA copies present in TG5E01 and both copies in TG5E04 segregated independently of one another, while the two copies in TG5E03 co-segregated (Figure 3 and 4A). A complete T-DNA has the size of $4762 \mathrm{bp}$. In the case of complete T-DNAs, the digestion of genomic DNA using HindIII is expected to result in hybridizing fragments larger than 3114 bp (Figure 4F), as was seen in all plants except the descendants from TG5E01, where the two fragments carrying copies \#2 and \#3 were smaller.
The derived structure of the transgenes in TG5E02 and TG5E03 was confirmed by PCR assays based on primer pairs spanning various parts of the two transgenes (Figure 4C-F); however, for TG5E01, the PCR analysis of $\mathrm{T}_{1}$ plant 6 carrying only the T-DNA copy \#3 (see Figure 3, plant lane 6) suggested that the HPT expression cassette was absent (Figure 4C,D,E, plant 6). Likewise, T-DNA copy \#2, which was present in TG5E01 $T_{1}$ plant 19 in addition to copy \#3, did not show amplicons in Figure $4 \mathrm{C}$ and upper $\mathrm{E}$ either, indicating that it was also truncated with respect to the HPT cassette. Another

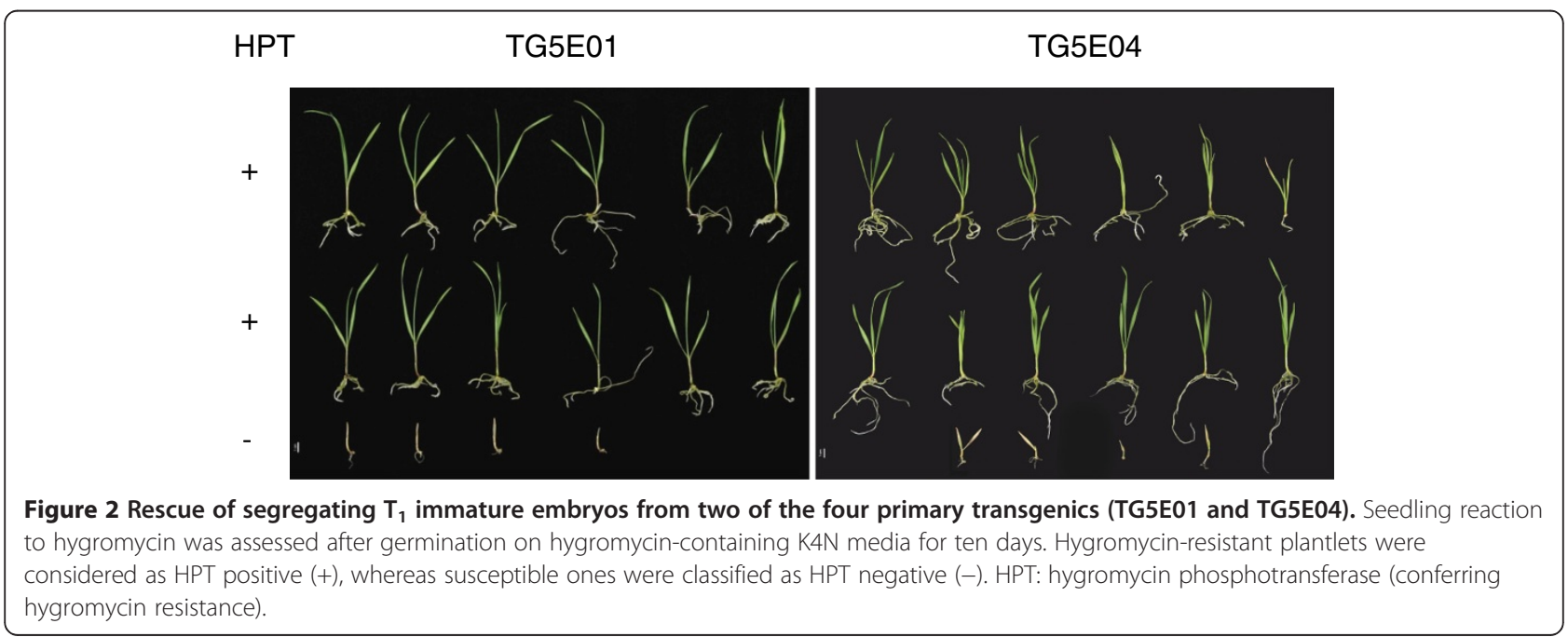


Table $2 \mathrm{~T}_{1}$ segregation for hygromycin resistance

\begin{tabular}{lcccccc}
\hline T plants & $\begin{array}{l}\text { T-DNA copies } \\
\text { (DNA gel blot) }\end{array}$ & $\begin{array}{l}\mathrm{T}_{\mathbf{1}} \text { plants } \\
\text { analyzed }\end{array}$ & $\begin{array}{l}\text { Hygromycin resistant/ } \\
\text { susceptible plants }\end{array}$ & $\begin{array}{l}\text { Segregation } \\
\text { ratio }\end{array}$ & $\begin{array}{l}\mathbf{X}^{\mathbf{2}} \text { value as to expected } \\
\text { ratio of 3:1 }\end{array}$ & $\begin{array}{l}\text { Likelihood (P) according } \\
\text { to } \mathbf{X}^{\mathbf{2}} \text { test }\end{array}$ \\
\hline TG5E01 & 3 & 73 & $59: 14$ & $4.2: 1$ & 1.8 & $>0.18$ \\
TG5E02 & 1 & 92 & $74: 18$ & $4.1: 1$ & 3.5 & $>0.05$ \\
TG5E03 & 2 & 96 & $54: 42$ & $1.3: 1$ & 24.8 & $<0.01$ \\
TG5E04 & 2 & 98 & $76: 22$ & $3.5: 1$ & 4.5 & $>0.05$ \\
\hline
\end{tabular}

Deviation from monogenic segregation (as shown by $x^{2}$ test) was only significant among the progeny of TG5E03.

example of incomplete T-DNA was found in TG5E04, where the single copy present in $\mathrm{T}_{1}$ plant 3 was truncated concerning the HPT expression cassette as revealed by PCR analysis (Figure 4E, upper band). Moreover, the also missing lower band in Figure $4 \mathrm{E}$ suggests another deletion in the promoter- $g f p$ junction, whereas the DNA gel blot analysis had demonstrated the presence of both the HPT and the $g f p$ sequences in this plant, and the internal $H P T$ and $g f p$ sequences were both successfully amplified.

\section{Transgene expression in the $T_{1}$ and $T_{2}$ generation}

When $T_{1}$ plant leaf segments were challenged with hygromycin, those carrying a functional copy of HPT remained green, whereas those lacking the transgene or a functional version became bleached (Figure 4B). In all cases, the outcome of the test concurred with the conclusions drawn from the PCR and/or DNA gel blot assays (Figure 4A-E). Note the intermediate reaction of the non-transformed control (Figure 4B), which suggested that this assay on its own is insufficiently diagnostic of the incorporation of a HPT transgene.

GFP was detectable in the root, leaf and mature caryopsis of plants carrying the single copy transgene (TG5E02)
(Figure 5A-H). In particular, the GFP signal was largely confined to cytosol. The level of $g f p$ expression varied considerably between cell types. In the leaf, it was highest in the chlorenchyma and the stomatal guard cells (Figure 5A,E). In the mature caryopsis, the most intense signal was present in the aleurone layer (Figure 5C, G) and in the nucellar projection (Figure 5D, H).

Twelve $\mathrm{T}_{2}$ populations and control descendants from an azygous $T_{1}$ segregant were tested for the expression of $g f p$ in the root tip (Table 3). As expected, some of these families segregated (TG5E01-12, TG5E03-1, TG5E03-7 and TG5E04-2), but it was possible to identify five nonsegregating (presumably transgene-homozygous) plants. All TG5E01-6 $\mathrm{T}_{2}$ individuals accumulated GFP (Table 3, Figure 6) although they only contain a truncated T-DNA fragment (for DNA gel blot see Figure 3 plant lane 6, for T-DNA truncation see Figure 4C-F). In this case, T-DNA truncation along with independent segregation of multiple T-DNAs unintendedly resulted in a selectable marker-free segregant that is homozygous with regard to the $g f p$ gene. By contrast, none of the TG5E04-3 $\mathrm{T}_{2}$ individuals tested expressed $g f p$, thereby confirming the missing PCR-fragment of the $g f p$ expression cassette from the respective $T_{1}$ plant as shown in Figure $4 \mathrm{E}$

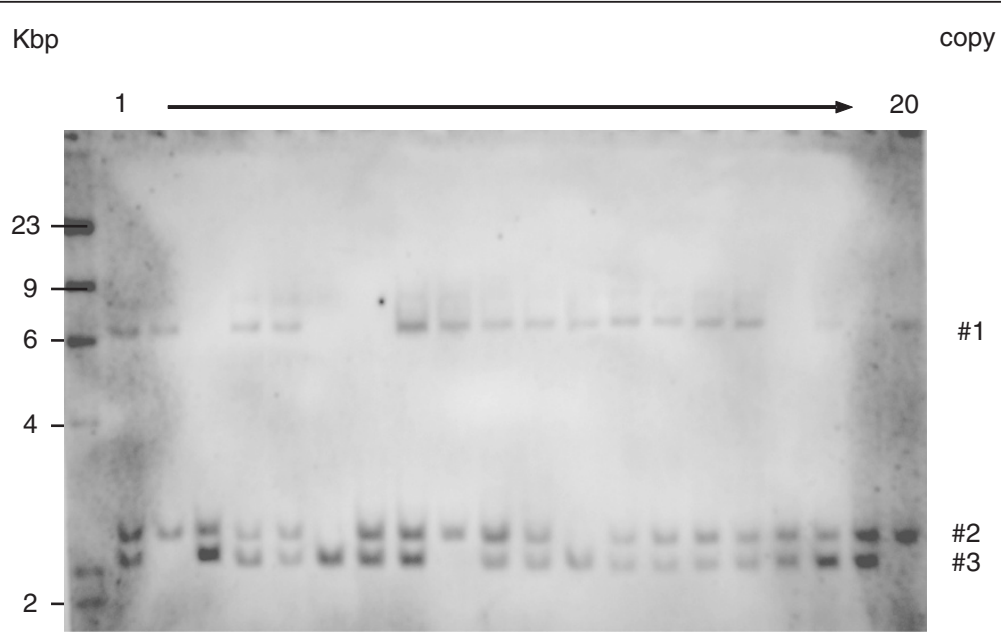

Figure 3 DNA gel blot analysis of TG5E01 $\mathrm{T}_{1}$ segregants. Genomic DNA was digested by Hindlll, gel separated and transferred onto a Hybond-N membrane and hybridized against a DIG labeled fragment of $\mathrm{gfp}$. The copy numbers were designated according to Tables 3 and 4. 


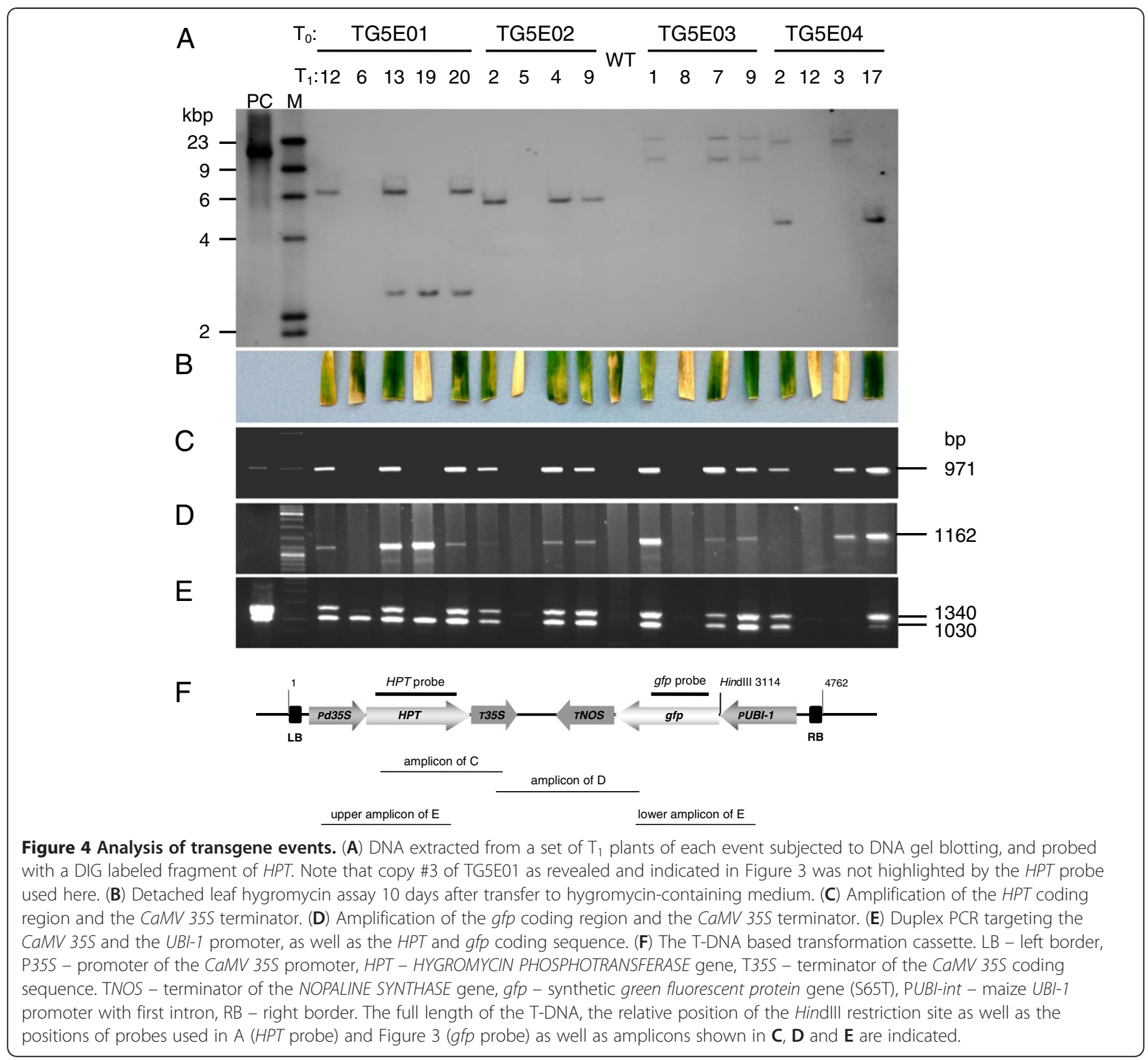

(lower band). Given the outcome of the leaf hygromycin test and the missing PCR fragments in the $T_{1}$ plant TG5E04-3 (Figure 4B,E and F), the conclusion drawn was that the transgene copy present in this plant comprised non-functional sequences with respect to both transgenes. All data regarding the integrity, functionality and segregation of the T-DNA copies are summarized in Table 4 . With regard to the gene-of-interest $(g f p)$, five out of eight independent transgene copies proved functional, while the presumed functionality of two further copies could not unequivocally be shown due to the presence of other T-DNAs. In all those cases, the observed phenotype could be explained by genotypic data of the plants.

\section{Discussion}

Our initial aim was to develop a robust protocol for the stable genetic transformation of winter triticale. The approach taken rested heavily on transformation protocols established for its parental species, wheat and rye. The amenability of immature embryos to co-cultivation with A. tumefaciens in liquid culture was trialed, as this provides an efficient means of processing immature embryos in barley [14], and the same approach is effective in rye [15]. Unfortunately, however, it does not seem to work well in wheat (unpublished data), where desiccation of the immature embryos appears to improve the transformation efficiency [16]. In practice, triticale behaved like wheat in this respect, as transformation was only 

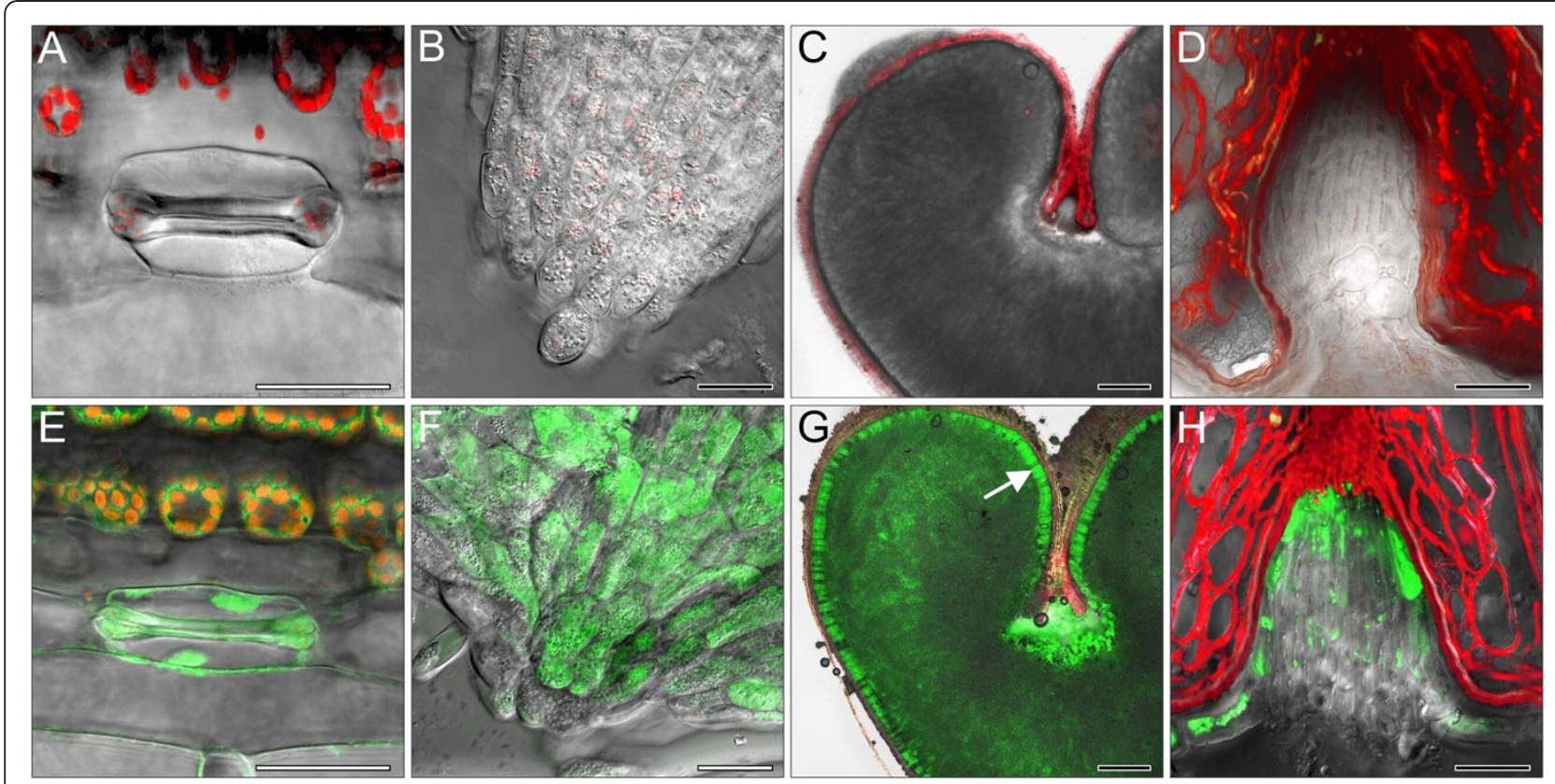

Figure 5 Localization of GFP accumulation using confocal laser scanning microscopy. Chlorenchyma cells and stomatal cells in the lower leaf epidermis of (A) non-transformed and (E) transgenic plants. (B) Non-transformed and (F) transgenic root tip. Transverse section through a mature $(\mathbf{C})$ non-transformed and $(\mathbf{G})$ transformed caryopsis, the latter showing a low level of GFP activity in the endosperm and a high level in the aleurone layer (arrow). Detail of a transverse section through a mature grain showing the nucellar projection in a (D) non-transformed and (H) transgenic plant. Very strong GFP activity was observed at the base and the lateral periphery of the nucellar projection. Chlorophyll or grain husk autofluorescence shown in red. Bars indicate $50 \mu \mathrm{m}$.

obtained when the immature embryos were co-cultivated on filter paper soaked with co-culture medium (Table 1). A similar study focusing on the spring triticale cultivar 'Wanad' compared the effectiveness of the three selectable marker genes BAR, HPT and NPTII driven by one of maize UBI-1, cauliflower mosaic virus $35 S$ or $A$. tumefaciens NOS promoter, respectively [12], and concluded that the best combination was NOS::NPTII, even though NOS performs poorly in a monocotyledonous host [17]. In the present study, the HPT selectable marker gene was preferred, a gene which has also proven useful e.g. in barley $[18,19]$, wheat and maize [13]. The

Table 3 Transgene segregation in twelve $T_{2}$ populations, based on gfp expression in seedling tissue

\begin{tabular}{|c|c|c|c|c|c|}
\hline $\mathrm{T}_{1}$ plants & $\begin{array}{l}\text { T-DNA copies } \\
\text { (DNA gel blot) }\end{array}$ & $\begin{array}{l}\mathrm{T}_{2} \text { plants } \\
\text { analyzed }\end{array}$ & $\begin{array}{l}\text { Segregation of } \\
\text { gfp expression }\end{array}$ & $\begin{array}{l}\text { Segregation ratio observed/ } \\
\text { (presumed for hemizygosity) }\end{array}$ & $\begin{array}{l}\text { Zygosity } \\
\text { concluded }\end{array}$ \\
\hline TG5E01-6 & $1(\# 3)$ & 25 & $25: 0$ & $25: 0(3: 1)$ & homozygous \\
\hline TG5E01-12 & $2(\# 1+\# 3)$ & 22 & $18: 4$ & $4.5: 1(15: 1)$ & hemizygous \\
\hline TG5E01-19 & $2(\# 2+\# 3)$ & 25 & $25: 0$ & $25: 0(15: 1)$ & homozygous ${ }^{\text {n.s. }}$ \\
\hline TG5E01-20 & $2(\# 1+\# 2)$ & 28 & 28:0 & $28: 0(15: 1)$ & homozygous n.s. \\
\hline TG5E02-2 & 1 & 22 & $22: 0$ & $22: 0(3: 1)$ & homozygous * \\
\hline TG5E02-4 & 1 & 17 & $17: 0$ & $17: 0(3: 1)$ & homozygous* \\
\hline TG5E02-9 & 1 & 20 & $20: 0$ & $20: 0(3: 1)$ & homozygous* \\
\hline TG5E03-1 & $2(\# 1+\# 2)$ & 21 & $7: 14$ & $1: 2(3: 1)$ & hemizygous \\
\hline TG5E03-7 & $2(\# 1+\# 2)$ & 20 & $4: 16$ & $1: 4(3: 1)$ & hemizygous \\
\hline TG5E03-8 & 0 & 20 & $0: 20$ & $0: 20$ & azygous \\
\hline TG5E04-2 & $2(\# 1+\# 2)$ & 18 & $14: 4$ & $3.5: 1(15: 1)$ & hemizygous \\
\hline TG5E04-3 & $1(\# 1)$ & 17 & $0: 17$ & $0: 17(3: 1)$ & unascertainable $^{1}$ \\
\hline TG5E04-12 & 0 & 14 & $0: 14$ & $0: 14$ & azygous \\
\hline
\end{tabular}

*) Significant, n.s.: not significant, according to $x^{2}$ test.

1) TG5E04-3 carries a non-functional copy of $g f p$. 

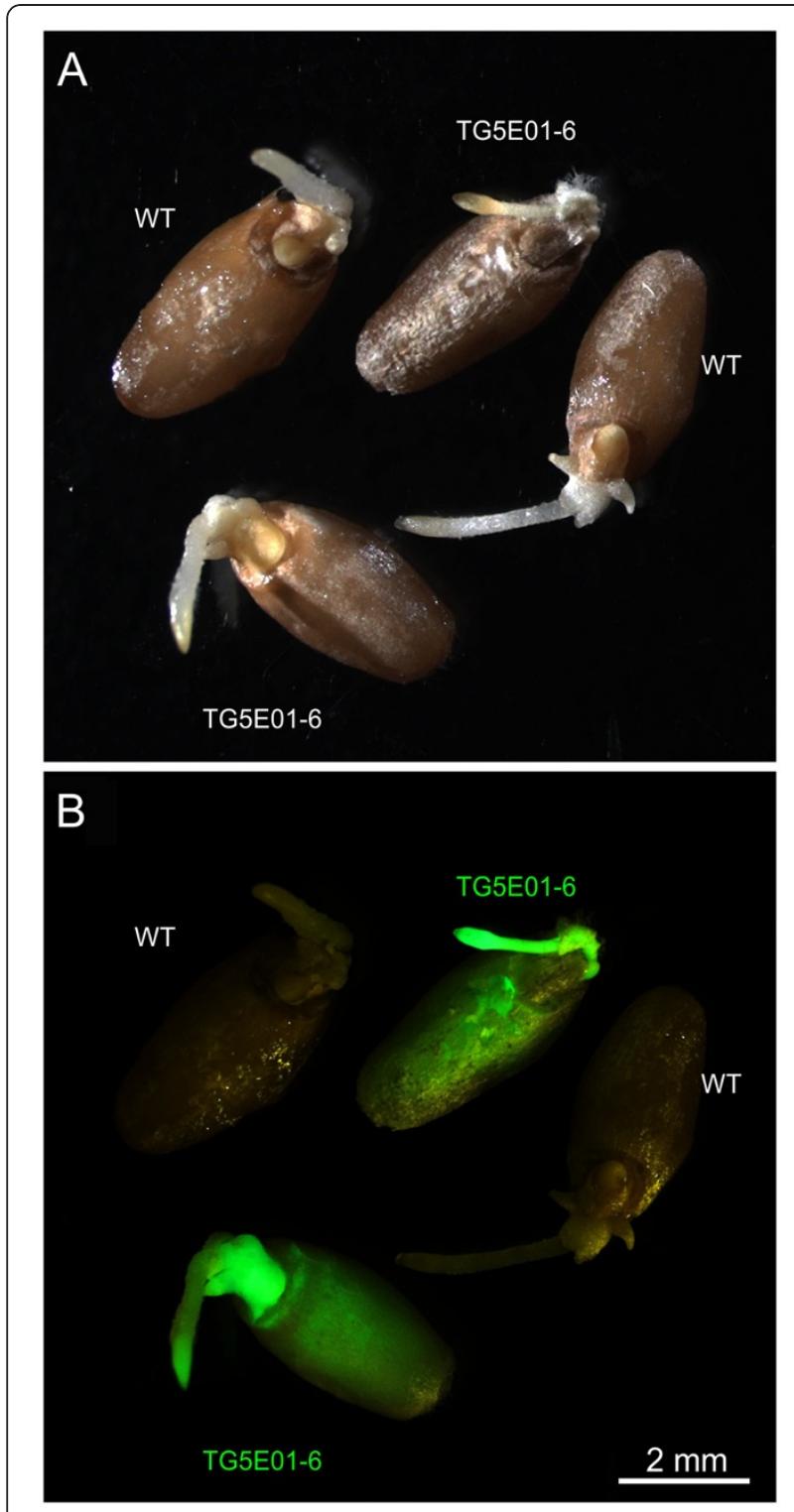

Figure 6 Reporter gene expression in $T_{2}$ grains after seven days of germination. (A) Illumination by white light and (B) excitation with far blue light; transgenic (TG5E01-6) and wild type (WT) control grains are indicated.

$g f p$ reporter gene was an efficient tool for monitoring transgenesis and the subsequent expression of the transgene (Figure 1F-J) [13,20].

Two of the three multiple T-DNA insertion events involved independent integration sites. In barley, $>50 \%$ of multiple transgenic events induced by agro-infection involved only one integration site [21]. A more comprehensive analysis of transformation outcomes has been made in Arabidopsis thaliana, where the number of T-DNA copies integrated at a single site appears to be dependent not only on the identity of the $A$. tumefaciens strain and the explant, but also on the transformation methodology as well as the origin of replication of the vector providing the T-DNA [22]. The occurrence of transformation events with multiple T-DNA copies being integrated in independent genomic loci of triticale opens up the opportunity to generate transgenic segregants with reduced copy number. Moreover, co-introduction of effector and selectable marker gene using two different T-DNAs may give rise to selectable marker-free transgenics after independent segregation of the loci in the $\mathrm{T}_{1}$. While a similar case unintendedly occurred in the present study (TG5E01 $\mathrm{T}_{1}$ plant 6 ), a directed approach using barley has recently been presented by Kapusi et al. [23]. Although Agrobacterium-mediated transformation generally results in the less frequent integration of truncated transgenes than biolistic transfer, as many as $44 \%$ of primary wheat transgenics have been shown to carry incomplete T-DNAs [24] with many involving truncations at the left T-DNA border [25]. In barley, meanwhile, only $3 \%$ (of 260 primary transgenics analysed) retained the full T-DNA [26]. Truncation of the T-DNA can be expected to result in a loss of transgene function, as was indeed the case in the present experiments that revealed truncations in $37.5 \%$ of the integrated T-DNAs analysed.

The non-Mendelian segregation of transgenes among $T_{1}$ progeny is a commonplace observation, and several hypotheses have been promoted to explain this phenomenon, such as $\mathrm{T}_{0}$ chimerism, multiple independently assorting insertion loci and transgene silencing induced by multiple transgene copies or DNA rearrangements [24,27-29]. In some cases, false positives can arise due to the expression of non-incorporated transgene cassettes including those carried by persisting Agrobacterium [30]. Non-Mendelian transgene segregation has been noted in triticale [12], but since this observation was based on a histochemical reporter gene assay and did not include any DNA analysis, its basis could not be ascertained. In the present study, fewer transgenic progeny was obtained than expected in the case of TG5E03, which suggests this plant to be chimeric with regard to transgenicity. This interpretation is corroborated by DNA gel blot, PCR and leaf assay, which indicated that all functional elements be present in at least one of the two coupled T-DNA copies (Figure 4A-F). Nonetheless, one of the copies may have produced aberrant mRNA causing post-transcriptional gene silencing. However, the non-Mendelian segregation observed in the $\mathrm{T}_{2}$ families derived from TG5E03 is anticipated to be caused solely by transgene silencing in some siblings, because chimerism can generally be ruled out in generations later than $\mathrm{T}_{0}$.

As monitored using confocal laser scanning microscopy, $g f p$ expression was widely distributed, but concentrated in the cytosol (Figure 5). This localization mirrors what has been observed in transgenic barley and wheat 
Table 4 The integrity, functionality and segregation of the T-DNA copies present in four primary transgenics

\begin{tabular}{|c|c|c|c|c|c|c|c|c|c|c|}
\hline \multirow{3}{*}{$\begin{array}{l}T_{0} \\
\text { T-DNA }\end{array}$} & \multicolumn{9}{|c|}{$T_{1}$} & \multirow{3}{*}{$\begin{array}{c}\frac{\mathrm{T}_{2}}{\text { Phenotype }} \\
\frac{\text { GFP }}{\text { (seedlings }}\end{array}$} \\
\hline & \multicolumn{4}{|c|}{ PCR } & \multicolumn{4}{|c|}{ DNA gel blot } & \multirow{2}{*}{ 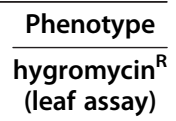 } & \\
\hline & P35S-HPT & HPT-T35S & PUBI1-gfp & gfp-TNOS & $\overline{H P T}$ & $g f p$ & $\underset{\text { segregation }}{g f p}$ & $\begin{array}{c}\text { integration } \\
\text { loci }\end{array}$ & & \\
\hline \multicolumn{11}{|l|}{ TG5E01 } \\
\hline copy \#1 & + & + & + & + & + & + & $14: 6(2.3: 1)$ & 3 & + & $+{ }^{b}$ \\
\hline copy \#2 & - & - & n.d. ${ }^{a}$ & + & + & + & $18: 2(9.0: 1)$ & - & & \\
\hline copy \#3 & - & - & + & - & - & + & $17: 3(5.6: 1)$ & & - & + \\
\hline \multicolumn{11}{|l|}{ TG5E02 } \\
\hline copy \#1 & + & + & + & + & + & + & 18:2 (9.0:1) & 1 & + & + \\
\hline \multicolumn{11}{|l|}{ TG5E03 } \\
\hline copy \#1 & $+{ }^{b}$ & $+{ }^{b}$ & $+{ }^{b}$ & $+{ }^{b}$ & + & + & $3: 17(0.2: 1)$ & $1^{c}$ & $+^{b}$ & $+{ }^{b}$ \\
\hline copy \#2 & & & & & + & + & & & & \\
\hline \multicolumn{11}{|l|}{ TG5E04 } \\
\hline copy \#1 & - & + & - & + & + & + & $11: 8(1.4: 1)$ & 2 & - & - \\
\hline copy \#2 & + & + & + & + & + & + & $12: 7(1.7: 1)$ & + & + & \\
\hline
\end{tabular}

a) Not determined, because an analysis independent of any of the two other copies was impossible.

b) Positive for at least one of the two transgene copies, however, these copies could not be analysed independent of one another.

c) Single case of this study where two T-DNA copies were co-integrated in one chromosomal locus.

[31], where the level of reporter gene expression in the aleurone and the endosperm was comparable to that driven by either the barley bi-functional $\alpha$-AMYLASE/ SUBTILISIN INHIBITOR (ISA) or the wheat EARLYMATURING (EM) promoter [31,32].

\section{Conclusion}

The transformation method used in the present study is a valuable tool for the genetic engineering of triticale. The availability of reliable transformation technology should encourage the application of current functional genomics technologies to triticale, and accelerate the biotechnological-based approach to its improvement. In the present study, we show that comprehensive molecular analyses are required for the correct interpretation of phenotypic data collected from transgenic plants.

\section{Methods}

\section{Plant material}

Grains of the winter triticale ( $x$ Triticosecale Wittmack) cultivar 'Bogo' were germinated at $14 / 12^{\circ} \mathrm{C}$ day/night under a $12 \mathrm{~h}$ photoperiod with a photon flux density during the light period of $136 \mu \mathrm{mol} \mathrm{s}{ }^{-1} \mathrm{~m}^{-2}$. After three weeks, the seedlings were vernalized by cultivating for eight weeks at $4^{\circ} \mathrm{C}$ under an $8 \mathrm{~h}$ photoperiod, re-potted and then grown in a glasshouse $\left(18 / 16^{\circ} \mathrm{C}\right.$ day/night, $16 \mathrm{~h}$ photoperiod, $170 \mu \mathrm{mol} \mathrm{s}^{-1} \mathrm{~m}^{-2}$ photon flux density).

\section{Choice of $A$. tumefaciens strain}

The hypervirulent $A$. tumefaciens strain AGL-1 was initially used for infection. The strain harbors the binary vector pYF133 [33] which provides CaMV d35S::HPT as a selectable marker gene, a synthetic $g f p$ sequence [34] driven by the maize UBI-1 promoter [35] as the reporter gene, and the PCAMBIA vector backbone [36] (Figure 7). The T-DNA borders are derived from a nopalineproducing Ti plasmid. Later experiments used a hypervirulent derivative of strain LBA4404 [37], which harbors the binary vector pSB187; this differs from pYF133 in the promoter chosen to drive HPT (CaMV 35S) and the vector backbone which was derived from pLH6000 [38] (Figure 7). Both pYF133 and pSB187 were introduced into $A$. tumefaciens via electroporation.

\section{Isolation of immature embryos and their pre-culture and co-cultivation with $A$. tumefaciens}

Immature caryopses were harvested 12-16 days post pollination, bathed for $3 \mathrm{~min}$ in $70 \%$ ethanol, further disinfected by immersion in $5 \% \mathrm{w} / \mathrm{v}$ sodium hypochlorite, $0.1 \% \mathrm{v} / \mathrm{v}$ Tween 20 for $15 \mathrm{~min}$ and washed five times in sterile, distilled water. Immature embryos were excised and plated scutellum side up on pre-cultivation medium as described elsewhere [13]. A frozen glycerol stock of A. tumefaciens $(200 \mu \mathrm{L}$ sampled from a culture with an $\mathrm{OD}_{600}$ of 2.0 suspended in $200 \mu \mathrm{L} 15 \% \mathrm{v} / \mathrm{v}$ glycerol) was seeded into $10 \mathrm{~mL}$ antibiotic-free CPY medium and cultured overnight at $28^{\circ} \mathrm{C}$ with shaking. Prior to inoculation, the pre-cultivated immature embryos were transferred into liquid co-cultivation medium (BCCM) [13], which was then immediately replaced by $600 \mu \mathrm{L} A$. tumefaciens culture. After vacuum infiltration $(1 \mathrm{~min}$ at 500 mbar), the immature embryos were washed with 


\section{pYF133}

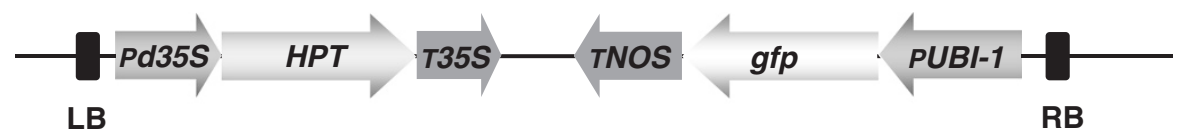

pSB187
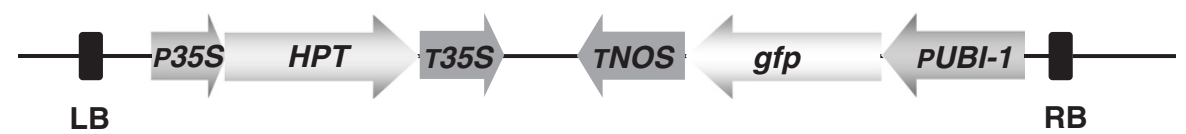

Figure 7 Schematic representation of T-DNA regions of the binary vectors used for transformation. LB - left border; Pd35S - CaMV double 35 S promoter; P35S - CaMV 355 promoter; HPT - HYGROMYCIN PHOSPHOTRANSFERASE selectable marker gene conferring resistance to hygromycin: T35S - CaMV 35 S terminator; TNOS - Agrobacterium NOPALINE SYNTHASE terminator; gfp - green fluorescent protein gene; PUBI-1 - maize UBIQUITIN-1 promoter; RB - right border.

BCCM. The pre-cultured and inoculated immature embryos were then either stacked on filter paper disks moistened with $300 \mu \mathrm{L} \mathrm{BCCM}$ or WCCM or incubated in $2.5 \mathrm{~mL}$ of the same media. The co-cultivation of explants and Agrobacterium took place in the dark at $21^{\circ} \mathrm{C}$ for $48-72 \mathrm{~h}$ without agitation. A total of $50 \mathrm{imma-}$ ture embryos divided into 5 sets comprising 10 embryos each were used per treatment.

\section{Tissue culture}

After co-cultivation, the immature embryos were transferred to BCIM [13] containing $150 \mathrm{mg} \cdot \mathrm{L}^{-1}$ timentin to kill any remaining A. tumefaciens. Calli formed over the following two weeks were transferred to BCIM containing $25 \mathrm{mg} \mathrm{L}^{-1}$ hygromycin and $150 \mathrm{mg} \mathrm{L}^{-1}$ timentin for a further two weeks and then removed to $\mathrm{K} 4 \mathrm{~N}$ regeneration medium [39] containing $25 \mathrm{mg} \mathrm{L}^{-1}$ hygromycin and $150 \mathrm{mg} \mathrm{L}^{-1}$ timentin. The cultivation plates were exposed to $136 \mu \mathrm{mol} \mathrm{s}^{-1} \mathrm{~m}^{-2}$ photon flux density over a $16 \mathrm{~h}$ photoperiod. Regenerating shoots were transferred to glass tubes containing the same medium until the plantlets were vigorous enough to be potted into soil.

\section{DNA analysis}

The PCR template comprised genomic DNA extracted from $100 \mathrm{mg}$ snap-frozen leaf using DNAzol (Invitrogen, Karlsruhe, Germany), according to the manufacturer's instructions. PCRs were based on the amplification of 100 ng template primed by the sequences listed in Table 5. Amplicons were separated by agarose gel electrophoresis and visualized by Ethidium bromide staining (Figure 4). Plants testing positive with the PCR assays were subjected to DNA gel blot analysis to characterize the integration site(s) and transgene copy number. At least $25 \mu \mathrm{g}$ genomic DNA, extracted as described in [40], was digested with HindIII, separated by agarose gel electrophoresis and blotted onto a Hybond $\mathrm{N}$ membrane. A gene-specific probe ( $g f p$ or $H P T$ ) was labeled with DIG as recommended by the supplier (Roche, Mannheim, Germany).

\section{Embryo rescue and segregation analysis of hygromycin resistance}

$\mathrm{T}_{1}$ caryopses were harvested $21-28$ days after pollination and the immature embryos were placed for $24 \mathrm{~h}$ on Gamborg's B5 medium [41] to induce germination. They were then transferred on to K4N medium [39] supplemented with $100 \mathrm{mg} \mathrm{L}^{-1}$ hygromycin, and held for up to ten days at $24^{\circ} \mathrm{C}$ under a $16 \mathrm{~h}$ photoperiod.

\section{Hygromycin leaf assay}

HPT expression in leaf segments of putative transgenic plants was analyzed following [42], attaching the leaf segments by their base to MS culture medium [43]

Table 5 Primer sequences used for the PCR analysis of putative transgenic regenerants

\begin{tabular}{ll}
\hline Primer & Sequence $\mathbf{5} \boldsymbol{\prime} \mathbf{-} \mathbf{3}$ ' \\
\hline 35S-F2-C & CATGGTGGAGCACGACACTCTC \\
35S-term-C & CATGAGCGAAACCCTATAAGAACCC \\
GH-35S-term-F1 & AATCACCAGTCTCTCTCTAC \\
GH-Hyg-F1 & GATCGGACGATTGCGTCGCA \\
GH-Hyg-R2 & TATCGGCACTTGCATCGGC \\
GH-Ubi-F3 & CCGTTCCGCAGACGGGATCGATCTAGGATAGGTA \\
GH-GFP-F1 & GGTCACGAACTCCAGCAGGA \\
GH-GFP-R2 & TACGGCAAGCTGACCCTGAA \\
\hline
\end{tabular}


containing $200 \mathrm{mg} \mathrm{L}^{-1}$ hygromycin and $0.05 \% \mathrm{v} / \mathrm{v}$ Tween 20. The plates were incubated for $7-10$ days at $24^{\circ} \mathrm{C}$ under a $16 \mathrm{~h}$ photoperiod.

\section{Microscopic analyses}

Florets were harvested prior to anthesis and pollen grains released into $0.4 \mathrm{M}$ mannitol. The expression of $g f p$ was analysed using an Axiovert 200M fluorescence microscope equipped with the 38HE filter set (Zeiss, Oberkochen, Germany). Leaf, root and mature grain samples were analyzed with a LSM 510 META confocal laser scanning microscope (Zeiss, Jena, Germany) using a $488 \mathrm{~nm}$ laser line for excitation. GFP signals were detected with a 505$530 \mathrm{~nm}$ band pass filter. Autofluorescence was recorded with a $650 \mathrm{~nm}$ long-pass filter.

\section{Competing interests}

The author(s) declare that they have no competing interests.

\section{Authors' contributions}

$\mathrm{GH}$ designed the transformation experiments, participated in the design and analysis of the molecular studies and drafted the manuscript. SO performed the transformation experiments and participated in drafting the manuscript. DD performed the microscopical studies. JZ and MM participated in the design and organisation of the study and helped to draft the manuscript. JK conceived of the study, and participated in its design and organisation and finalized the manuscript. All authors read and approved the final manuscript.

\section{Acknowledgements}

The authors thank Cornelia Marthe for her excellent technical assistance. We also thank Dr. Sylvia Broeders for providing the vector pSB187.

\section{Author details}

${ }^{1}$ Leibniz Institute of Plant Genetics and Crop Plant Research (IPK), Plant Reproductive Biology, Corrensstr. 3, 06466, Gatersleben, Germany. ²Plant Breeding and Acclimatization Institute, National Research Institute, Radzików, 05-870, Błonie, Poland. ' Leibniz Institute of Plant Genetics and Crop Plant Research (IPK), Structural Cell Biology, Corrensstr. 3, 06466, Gatersleben, Germany. ${ }^{4}$ National Gene Bank and Genetic Resources, Agriculture Research Center, 12619, Giza, Egypt.

Received: 2 April 2012 Accepted: 21 September 2012

Published: 25 September 2012

\section{References}

1. Food and Agriculture Organization of the United Nations. http://faostat.fao. org/site/567/DesktopDefault.aspx?PagelD=567\#ancor.

2. Stolarz A, Lörz H: Protoplast culture and transformation studies of triticale (x Triticosecale Wittmack). Plant Cell Tiss Org Cult 1988, 12:227-230.

3. Zimny J, Rafalski A: Transformation study on triticale protoplasts. Bull Inst Plant Breed Acclim 1993, 197:127-132.

4. Immonen AST: Amino acid medium for somatic embryogenesis from immature triticale (x Triticosecale Wittmack) embryos. Cer Res Comm 1993, 21:51-55.

5. Ainsley PJ, Aryan AP: Efficient plant regeneration system for immature embryos of triticale ( $x$ Triticosecale Wittmack). Plant Growth Regul 1998, 24:23-30.

6. Vikrant, Rashid A: Comparative study of somatic embryogenesis from immature and mature embryos and organogenesis from leaf-base of triticale. Plant Cell Tiss Organ Cult 2001, 64:33-38.

7. Birsin MA, Ozgen M: A comparison of callus induction and plant regeneration from different embryo explants of triticale ( $x$ Triticosecale Wittmack). Cell Mol Biol Lett 2004, 9:353-361.
8. Zimny J, Becker D, Brettschneider R, Lörz H: Fertile transgenic triticale (x Triticosecale Wittmack). Mol Breed 1995, 1:155-164.

9. Rubio S, Jouve N, Gonzalez JM: Biolistic transfer of the gene uidA and its expression in haploid embryo-like structures of triticale ( $x$ Triticosecale Wittmack). Plant Cell Tiss Organ Cult 2004, 77:203-209.

10. Doshi KM, Eudes E, Laroche A, Gaudet D: Anthocyanin expression in marker free transgenic wheat and triticale embryos. In Vitro Cell Dev Biol Plant 2007, 43:429-435.

11. Rubio Diaz S: Transformación genética en trigo común ("Triticum aestivum" L.) y triticale ("XTriticosecale" Wittmack) mediante biolística y "Agrobacterium tumefaciens": PhD thesis Universidad de Alcalá. Departamento de Biología Celular y Genética; 2005. http://dspace.uah.es/dspace/handle/10017/790? show=full.

12. Nadolska-Orczyk A, Przetakiewicz A, Kopera K, Binka A, Orczyk W: Efficient method of Agrobacterium-mediated transformation for triticale (x Triticosecale Wittmack). J Plant Growth Regul 2005, 24:2-10.

13. Hensel G, Kastner C, Oleszczuk S, Riechen J, Kumlehn J: Agrobacteriummediated gene transfer to cereal crop plants: Current protocols for barley, wheat, triticale and maize. Int J Plant Genomics 2009, 2009 (Article ID 835608):9. doi:10.1155/2009/835608.

14. Hensel G, Valkov V, Middlefell-Williams J, Kumlehn J: Efficient generation of transgenic barley: the way forward to modulate plant-microbe interactions. J Plant Physiol 2008, 165:71-82.

15. Popelka JC, Altpeter F: Agrobacterium tumefaciens-mediated genetic transformation of rye (Secale cereale L.). Mol Breed 2003, 11:203-211.

16. Jones HD: Wheat transformation: current technology and applications to grain development and composition. J Cereal Sci 2005, 41:137-147.

17. Fromm M, Taylor LP, Walbot $V$ : Expression of genes transferred into monocot and dicot plant cells by electroporation. Proc Natl Acad Sci USA 1985, 82:5824-5828.

18. Matthews PR, Wang MB, Waterhouse PM, Thornton S, Fieg SJ, Gubler F, Jacobsen JV: Marker gene elimination from transgenic barley, using co-transformation with adjacent 'twin T-DNAs'on a standard Agrobacterium transformation vector. Mol Breed 2001, 7:195-202.

19. Coronado MJ, Hensel G, Broeders S, Otto I, Kumlehn J: Immature pollen-derived doubled haploid formation in barley cv. Golden Promise as a tool for transgene recombination. Acta Physiol Plant 2005, 27:591-599.

20. Hensel G, Kumlehn J: Genetic transformation of barley (Hordeum vulgare L.) by co-culture of immature embryos with Agrobacteria. In Transgenic crops of the world - Essential protocols. Edited by Curtis IS. Dordrecht Kluwer; 2004:35-43. http://www.springerlink.com/content/ r562864662v571mk/.

21. Stahl $R$, Horvath $H$, Van Fleet J, Voetz $M$, von Wettstein D, Wolf N: T-DNA integration into the barley genome from single and double cassette vectors. Proc Natl Acad Sci USA 2002, 99:2146-2151.

22. De Buck S, Podevin N, Nolf J, Jacobs A, Depicker A: The T-DNA integration pattern in Arabidopsis transformants is highly determined by the transformed target cell. Plant J 2009, 60:134-145.

23. Kapusi E, Hensel G, Coronado MJ, Broeders S, Marthe C, Otto I, Kumlehn J: The elimination of a selectable marker gene in the doubled haploid progeny of co-transformed barley plants. Plant Mol Biol, . under revision.

24. Cheng M, Frey JE, Pang S, Zhou H, Hironaka CM, Duncan DR, Conner TW, Wan Y: Genetic transformation of wheat mediated by Agrobacterium tumefaciens. Plant Physiol 1997, 115:971-980.

25. Wu H, Sparks CA, Jones HD: Characterisation of T-DNA loci and vector backbone sequences in transgenic wheat produced by Agrobacterium-mediated transformation. Mol Breed 2006, 18:195-208.

26. Bartlett JG, Alves SC, Smedley M, Snape JW, Harwood WA: High-throughput Agrobacterium-mediated barley transformation. Plant Methods 2008, 4:22.

27. Hiei Y, Ohta S, Komari T, Kumashiro T: Efficient transformation of rice (Oryza sativa L.) mediated by Agrobacterium and sequence analysis of the boundaries of the T-DNA. Plant J 1994, 6:271-282.

28. Ishida Y, Saito H, Ohta S, Hiei Y, Komari T, Kumashiro T: High efficiency transformation of maize (Zea mays L.) mediated by Agrobacterium tumefaciens. Nat Biotechnol 1996, 14:745-750.

29. Zhang S, Cho MJ, Koprek T, Yun R, Bregitzer P, Lemaux PG: Genetic transformation of commercial cultivars of oat (Avena sativa L.) and barley (Hordeum vulgare L.) using in vitro shoot meristematic 
cultures derived from germinated seedlings. Plant Cell Rep 1999, 18:959-966.

30. Langridge P, Brettschneider R, Lazzeri P, Lorz H: Transformation of cereals via Agrobacterium and the pollen pathway - a critical assessment. Plant $J$ 1992, 2:631-638.

31. Furtado A, Henry RJ, Pellegrineschi A: Analysis of promoters in transgenic barley and wheat. Plant Biotechnol J 2009, 7:240-253.

32. Furtado A, Henry RJ: The wheat Em promoter drives reporter gene expression in embryo and aleurone tissue of transgenic barley and rice. Plant Biotechnol I 2005, 3:421-434.

33. Fang YD, Akula C, Altpeter F: Agrobacterium-mediated barley (Hordeum vulgare $\mathrm{L}$.) transformation using green fluorescent protein as a visual marker and sequence analysis of T-DNA::barley genomic DNA junctions. J Plant Physiol 2002, 159:1131-1138.

34. Chiu WL, Niwa Y, Zeng W, Hirano T, Kobayashi H, Sheen J: Engineered GFP as a vital reporter in plants. Curr Biol 1996, 6:325-330.

35. Christensen AH, Quail PH: Ubiquitin promoter-based vectors for high-level expression of selectable and/or screenable marker genes in monocotyledonous plants. Transgen Res 1996, 5:213-218.

36. CAMBIA: Australia. http://www.cambia.org.au

37. Komari T, Hiei Y, Saito Y, Murai N, Kumashiro T: Vectors carrying two separate T-DNAs for co-transformation of higher plants mediated by Agrobacterium tumefaciens and segregation of transformants free from selection markers. Plant J 1996, 10:165-174.

38. Hausmann L, Töpfer R: Entwicklung von Plasmid-Vektoren. In: Vorträge für Pflanzenzüchtung. 1999, 45:153-171.

39. Kumlehn J, Serazetdinova L, Hensel G, Becker D, Loerz H: Genetic transformation of barley (Hordeum vulgare L.) via infection of androgenetic pollen cultures with Agrobacterium tumefaciens. Plant Biotechnol J 2006, 4:251-261.

40. Pallotta MA, Graham RD, Langridge P, Sparrow DHB, Barker SJ: RFLP mapping of manganese efficiency in barley. Theor Appl Genet 2000, 101:1100-1108.

41. Gamborg O, Miller R, Ojima K: Nutrient requirement of suspension cultures of soybean root cells. Exp Cell Res 1968, 50:151-158.

42. Wang MB, Waterhouse PM: A rapid and simple method of assaying plants transformed with hygromycin or ppt resistance genes. Plant Mol Biol Rep 1997, 15:209-215.

43. Murashige T, Skoog F: A revised medium for rapid growth and bioassays with tobacco tissue cultures. Physiol Plant 1962, 15:473-479.

doi:10.1186/1471-2229-12-171

Cite this article as: Hensel et al: Analysis of T-DNA integration and generative segregation in transgenic winter triticale (x Triticosecale Wittmack). BMC Plant Biology 2012 12:171.

\section{Submit your next manuscript to BioMed Central and take full advantage of:}

- Convenient online submission

- Thorough peer review

- No space constraints or color figure charges

- Immediate publication on acceptance

- Inclusion in PubMed, CAS, Scopus and Google Scholar

- Research which is freely available for redistribution

Submit your manuscript at www.biomedcentral.com/submit
(O) Biomed Central 